Kocaeli Journal of Science and Engineering

\title{
A Case Study on the Assumption of Mean Radiant Temperature Equals to Indoor Air Temperature in a Free-Running Building
}

\author{
Mehmet Furkan ÖZBEY ${ }^{1}$ (iD), Cihan TURHAN ${ }^{2, *}$ (iD \\ ${ }^{1}$ Department of Mechanical Engineering, Atllim University, Ankara, 06830, Turkey, ORCID: 0000-0002-5813-3514 \\ ${ }^{2}$ Department of Energy Systems Engineering, Atılım University, Ankara, 06830, Turkey, ORCID: 0000-0002-4248-431X
}

Article Info

Research paper

Received : November 30, 2020

Accepted : March 15, 2021

Keywords

Adaptive Thermal Comfort

Free Running Building

Globe Thermometer

Indoor Air Temperature

Mean Radiant Temperature

\author{
Abstract
}

Thermal comfort is basically affected by environmental (mean radiant temperature, indoor air temperature and relative humidity and air velocity) and personal parameters (clothing value and activity level). Mean Radiant Temperature is the most complicated parameter among all thermal comfort parameters due to the difficulty of measurement and calculation processes. Calculation methods are not preferred by the researchers because of the complexity of obtaining angle factors while the measurement methods require very expensive devices such as globe thermometers and radiometers. On the other hand, assumptions are commonly used in thermal comfort studies because of their simplicities. One of the most frequently used assumptions expresses the equality of mean radiant temperature to indoor air temperature. However, the accuracy of this assumption needs further experimental research in order to evaluate thermal comfort, especially in free-running buildings. To this aim, this study proposes to determine the accuracy of the assumption of mean radiant temperature equals to indoor air temperature in a free-running building where Adaptive Thermal Comfort approach is applied in summer condition. Environmental parameters are measured via objective sensors, while adaptive thermal comfort is assessed by a software program. The statistical results show that there are significant deviations between two parameters in summer conditions for a free-running building.

\section{Introduction}

The main concerns on thermal comfort are traditionally assessed with Fanger's Predicted Mean Vote (PMV) and Predicted Percentage of Dissatisfied (PPD) method for air-conditioned and/or mixed-mode buildings [1-3]. However, free-running buildings are without indoor climate control such as heating, cooling and ventilation [4]. Occupants have wider tolerance on their discomfort since windows and/or doors are allowed to be open when an occupant wants to re-satisfy thermal comfort in the indoor environment [5]. For free-running buildings, Adaptive Thermal Comfort (ATC) models are applied by using linear correlations linking an optimal comfort temperature to mean outdoor temperature [6-7]. Thus, obtaining

\footnotetext{
*Corresponding Author: cihan.turhan@ atilim.edu.tr
}

operative temperature (OT) is vital to obtain accurate thermal comfort for free-running buildings. In the calculation of OT, Mean Radiant Temperature (MRT), Indoor Air Temperature $\left(\mathrm{T}_{\mathrm{i}}\right)$ and Air Velocity $\left(v_{a}\right)$ are included [8]. In a free-running building, air velocity is uncontrolled since there is no ventilation controlling. For this reason, MRT and $\mathrm{T}_{\mathrm{i}}$ values generally vary, which makes thermal comfort models difficult to obtain [9].

MRT is defined as "the temperature of a uniform, black enclosure that exchanges the same amount of heat by radiation with the occupant as the actual enclosure" in ASHRAE Standard 55 [1] and measured by globe thermometer, radiometers and constant air temperature sensors. However, the price of the sensors is very high, and the usage of these devices require highly skilled and expert users. On the other hand, calculation methods are very complicated due to determine the angle factors of the occupant $[10,11]$. Instead of calculation and measurement methods, the researchers prefer to use the assumption of 
the equality of MRT and $\mathrm{T}_{\mathrm{i}}$ [1,12-15]. However, the accuracy of the assumption is always a question mark for free running and/or air-conditioned buildings. To this aim, some researchers compare the assumption of the equality of MRT and $\mathrm{T}_{\mathrm{i}}$. In the studies, the comparison of the MRT and $T_{i}$ values are assessed with an equivalent ratio [16]. For instance, Koch [17] studied the relationship between the MRT and $\mathrm{T}_{\mathrm{i}}$ in ranges of $22.7^{\circ} \mathrm{C}$ to $29.9^{\circ} \mathrm{C}$ and $21.2^{\circ} \mathrm{C}$ to $26.9^{\circ} \mathrm{C}$ for $\mathrm{T}_{\mathrm{i}}$ and $\mathrm{MRT}$, respectively, in mechanically ventilated buildings with 12 different measurement data. As a result of the study, MRT and $\mathrm{T}_{\mathrm{i}}$ had a difference up to $1.5^{\circ} \mathrm{C}$, and the equivalent ratio was found as 0.669 . In another study, McIntyre et al. [18] used 33 measurements between a range of $20.8^{\circ} \mathrm{C}$ to $23.8^{\circ} \mathrm{C}$ and $24^{\circ} \mathrm{C}$ to $28.5^{\circ} \mathrm{C}$ for $T_{i}$ and MRT, respectively. The authors found the equivalent ratio as 0.791 . Lin et al. [19] conducted research in mixed type buildings that have different heating systems of the radiator, radiant floor heating and all-air heating systems. The results showed that the difference between MRT and $\mathrm{T}_{\mathrm{i}}$ was between $-0.5^{\circ} \mathrm{C}$ to $+0.5^{\circ} \mathrm{C}$. Catalina et al. [20] handled research in the mixed type test chamber by using radiant ceiling panels and found $0.8^{\circ} \mathrm{C}$ difference between $\mathrm{T}_{\mathrm{i}}$ and OT. The most blazing research was conducted by Dave et al. [15] that used over 200.000 measurement data in 48 different mechanically conditioned office buildings. The results demonstrated that the median absolute difference between the MRT and $\mathrm{T}_{\mathrm{i}}$ was $0.4^{\circ} \mathrm{C}$.

The assumption of the equality of MRT to $\mathrm{T}_{\mathrm{i}}$ causes uncertainty on thermal comfort results. For instance, Chaudhuri et al. [21] investigated the effect of using the equality of MRT and $\mathrm{T}_{\mathrm{i}}$ on the PMV in air-conditioned buildings. The experiments proved that using this assumption cause an error to the PMV value up to 1.54 PMV difference. Furthermore, De Dear and Brager [5] found that this assumption overestimated the occupant responses on ASHRAE 55 scales in high temperatures while using PMV/PPD method, which was originally created for air-conditioned buildings, in free-running buildings.

Even though the studies on the accuracy of the equality of MRT to $T_{i}$ are common in air-conditioned buildings, the studies on the accuracy of the assumption are very limited for free-running buildings, especially in temperate climate zone. To this aim, this study investigates the accuracy of the assumption of MRT to $T_{i}$ for a freerunning building in a temperate climate zone by using ATC approach.

\section{Materials and Methods}

A free-running case-building $(4.7 \mathrm{~m}$ depth $\times 3.25 \mathrm{~m}$ width $\mathrm{x} 2.75 \mathrm{~m}$ height) was selected in a university campus in Ankara, Turkey which is located in Csb-type climate zone according to the Köppen-Geiger Climate Classification [22]. The case building includes a largeglazed window (window to wall ratio is 3.6) in the south direction. Since the case building is a free-running building, Heating Ventilating, and Air Conditioning (HVAC) system does not exist, and the building is ventilated naturally. An outlook and architectural drawing of the case building are depicted in Figures 1 and 2, respectively.

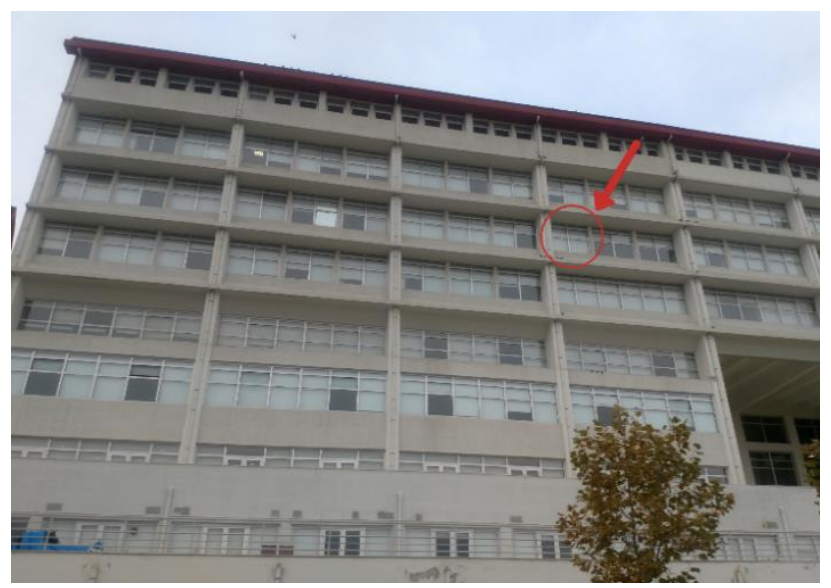

Figure 1. The outlook of the case building.

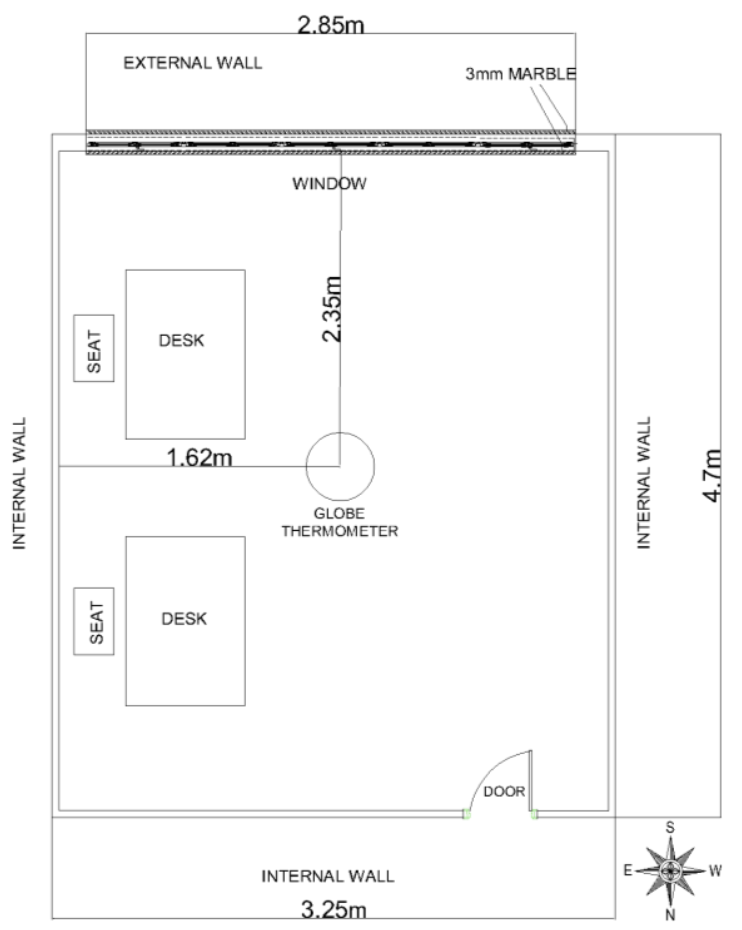

Figure 2. Architectural drawing of the case building.

The methodology of the study consists of three separate sub-sections, namely, measurements of $\mathrm{T}_{\mathrm{i}}, \mathrm{T}_{\mathrm{g}}$ and $v_{a}$, determining the MRT and OT via using Eq. (1) and Eq. (2) and comparison of the results to determine the accuracy of the assumption as shown in Figure 3. 


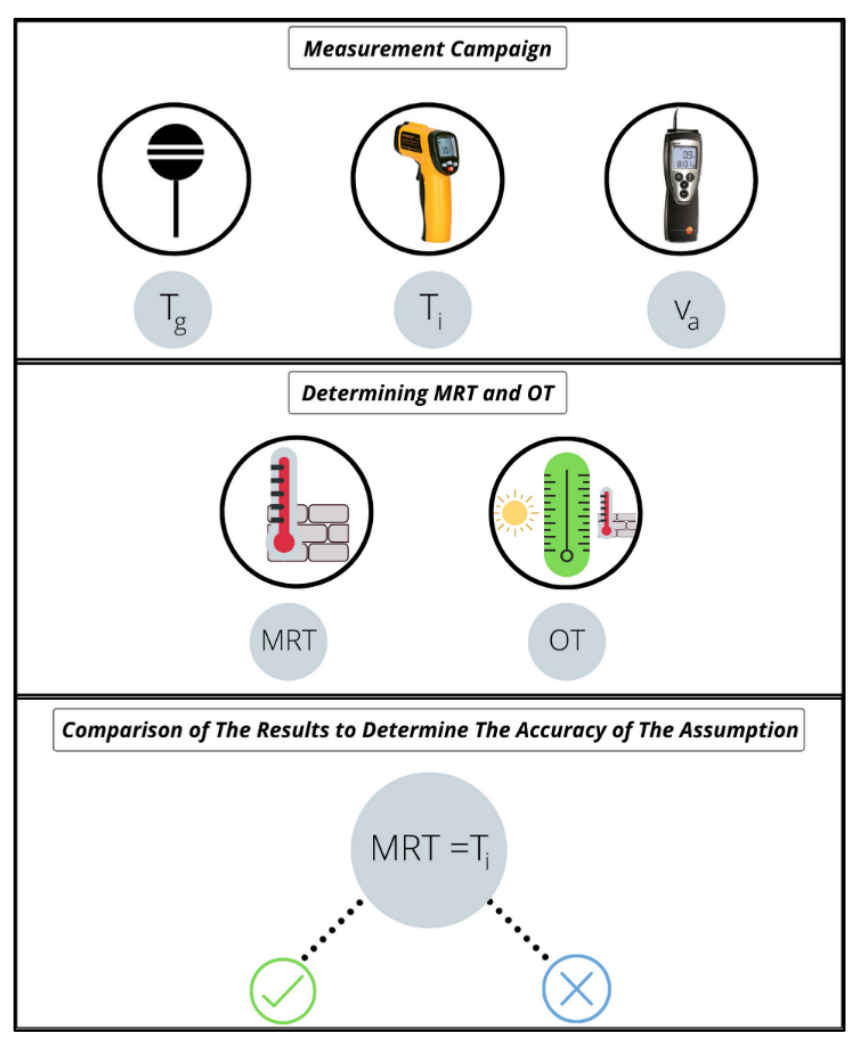

Figure 3. The methodology of the study.

The MRT, $v_{a}$, and $\mathrm{T}_{\mathrm{i}}$ measurements were taken on weekdays from 09:00 to12:00 and from 13:00 to 17:00 with a 10 -min interval between $15^{\text {th }}$ of July 2020 and $6^{\text {th }}$ of October 2020 including summer season. During the measurements, one male occupant was seated (metabolic rate value: 1 met) and occupant could open and/or closed the window and door, and the occupant was allowed to freely adopt clothing insulation to ensure thermal comfort since ATC standards were applied [23]. Besides, the outdoor temperature $\left(\mathrm{T}_{\mathrm{o}}\right)$ values were taken from Meteorological Station of the university.

$\mathrm{T}_{\mathrm{i}}$ values were taken with an infrared thermometer EXTECH Measurements 42530 [24] - and $v_{a}$ was measured with an anemometer - TESTO 425 [25] -inside the case building. The utilized devices in the measurement campaign and their specifications are indicated in Table 1.

Table 1. Utilized devices for measurements of $\mathrm{T}_{\mathrm{i}}$ and $v_{a}$.

\begin{tabular}{|c|c|c|}
\hline Device & Model & Specification \\
\hline $\begin{array}{c}\text { Infrared } \\
\text { Thermometer }\end{array}$ & $\begin{array}{c}\text { EXTECH } \\
\text { Measurements } \\
42530[24]\end{array}$ & $\begin{array}{c}\text { Accuracy } \pm 2 \% \\
\text { Resolution: } 0.1{ }^{\circ} \mathrm{C}\end{array}$ \\
\hline Anemometer & $\begin{array}{c}\text { TESTO } 425 \\
{[25]}\end{array}$ & $\begin{array}{c}\text { Accuracy: } \pm(0.03 \mathrm{~m} / \mathrm{s} \\
+5 \% \text { of Measured } \\
\text { Value }) \\
\text { Resolution: } 0.1 \mathrm{~m} / \mathrm{s}\end{array}$ \\
\hline
\end{tabular}

On the other hand, the MRT values were obtained from a developed Globe Thermometer (GT) by the authors. The developed GT has $135 \mathrm{~mm}$ diameter with $0.6 \mathrm{~mm}$ thick matt-black copper globe and k-type thermometer in the middle of the copper sphere. It is worth to note that the GT was calibrated with an industrial well-known globe thermometer. The MRT was calculated by using the Eq. (1), which is also indicated in ISO 7726 [26].

$M R T=\left[\left(T_{g}+273\right)^{4}+\frac{0.25 \times 10^{8}}{\varepsilon_{g}}\left(\frac{\left|T_{g}-T_{i}\right|}{D}\right)^{\frac{1}{4}}\left(T_{g}-T_{i}\right)\right]^{\frac{1}{4}}-273$

where $\mathrm{T}_{\mathrm{g}}$ represents the globe temperature, $\varepsilon_{g}$ defines emissivity of the globe, which is 0.95 for matt-black copper [26], and D is the diameter of the globe.

In ATC models, the OT, defined as the temperatures of a body that can achieve in its natural environment, was used [1,27,28] and calculated, as shown in Eq. (2).

$O T=T_{i}+(1-A)\left(M R T-T_{i}\right)$

where A is equal to 0.5 if $v_{a}$ is lower than $0.2 \mathrm{~m} / \mathrm{s}, 0.6$ if the $v_{a}$ is between $0.2 \mathrm{~m} / \mathrm{s}$ to $0.6 \mathrm{~m} / \mathrm{s}$ and 0.7 if the $v_{a}$ between $0.7 \mathrm{~m} / \mathrm{s}$ to $1 \mathrm{~m} / \mathrm{s}$.

In order to check the accuracy of the assumption, the null hypothesis $\left(\mathrm{H}_{\mathrm{o}}\right)$ and the alternative hypothesis $\left(\mathrm{H}_{1}\right)$ were constructed as; "There is no difference between the MRT and $T_{i}$ in a free-running building $\left(M R T=T_{i}\right)$ ") and "There is a difference between the MRT and $T_{i}$ in a freerunning building $\left(M R T \neq T_{i}\right)$ ", respectively.

The determination of the accuracy of assumption was provided with well-known statistical criteria which are Mean Squared Error (MSE) (Eq. (3)) and Determination of Multiple Coefficient ( $\mathrm{R}^{2}$ ) (Eq. (4)) by using the MRT data stem from $\mathrm{GT}$ and $\mathrm{T}_{\mathrm{i}}$.

$M S E=\frac{1}{p} \sum\left|z_{i}-o_{i}\right|$

$R^{2}=1-\left(\frac{\sum_{i}\left|z_{i}-o_{i}\right|^{2}}{\sum_{i} o_{i}}\right)$

where $o_{i}$ represents the output, $z_{i}$ defines the target, and $p$ is the number of input-output pairs of $i^{\text {th }}$ data [29,30].

Moreover, two-tailed t-test was used in the study in order to check the accuracy of the hypotheses (Eq. (5)). The significance level was selected as $5 \%$ [31,32].

$t=\frac{\overline{x_{a}}-\overline{x_{b}}}{\sqrt{\frac{s_{a}^{2}}{n_{a}}+\frac{s_{b}^{2}}{n_{b}}}}$

where $\overline{x_{a}}$ and $\overline{x_{b}}$ represents the means, $S_{a}^{2}$ and $S_{b}^{2}$ defines 
standard deviation and $n_{a}$ and $n_{b}$ are the sample sizes of $\mathrm{Ti}$ and MRT, respectively.

In the final step, ATC graphs were drawn in order to compare both cases in different acceptance levels of $80 \%$ and $90 \%$. The ATC acceptable upper and lower limits were described in Eqs. (6) and (7) for $80 \%$ acceptance limits and Eqs. (8) and (9) for 90\% acceptance limits [1,33].

Upper Limit $_{80 \%}=0.31 T_{\text {out }}+21.3$

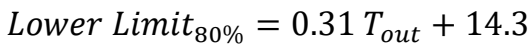

Upper Limit $_{90 \%}=0.31 T_{\text {out }}+20.3$

Upper Limit $_{90 \%}=0.31 T_{\text {out }}+15.3$

\section{Results and Discussion}

The MRT and $T_{i}$ data were examined in order to determine the variation between two parameters and to check the accuracy of the null hypothesis, which was identified in Eq. (5). Moreover, Figure 4 represents the comparison of MRT and $\mathrm{T}_{\mathrm{i}}$ data while the results of regression analysis are expressed in Table 2.

Figure 5 depicts the results of $\mathrm{T}_{\mathrm{i}}$, MRT, OT with respect to $T_{o}$ values. Since the study was conducted in the summer season, the MRT values were found higher than $T_{i}$ values.

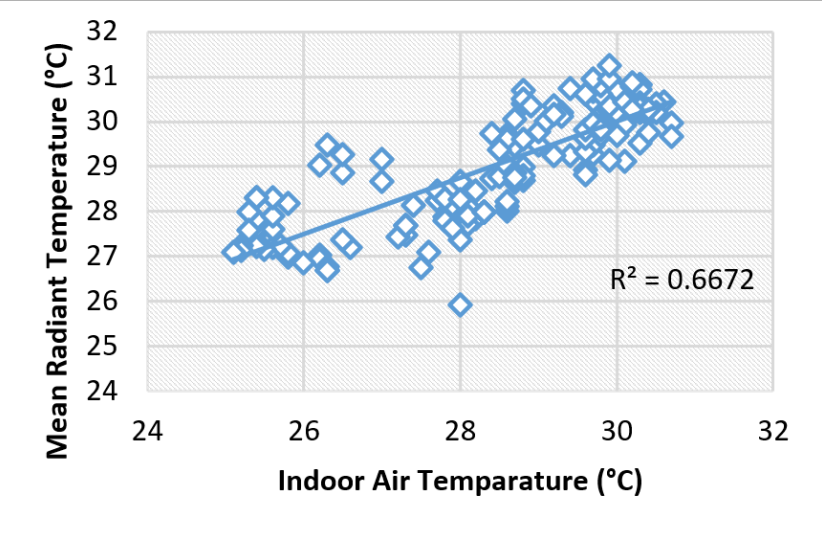

Figure 4. Comparison of measured MRT and $\mathrm{T}_{\mathrm{i}}$ data with linear comparison method.

Table 2. Results of Regression Analysis

\begin{tabular}{|c|c|}
\hline Slope & 0.63 \\
\hline Intercept & 11.08 \\
\hline MSE & 1.22 \\
\hline $\mathbf{R}^{\mathbf{2}}$ & 0.66 \\
\hline
\end{tabular}

The linear comparison analysis demonstrated that MRT and $T_{i}$ had exceedingly different values with a $R^{2}$ value of 0.66 and MSE of 1.22. MRT is generally bigger than $T_{i}$ because the temperature of the glazing surface is greater than $T_{i}$ and the short-wave solar radiation is significantly high in the summer season. The equivalent ratio was found as 0.85 . In comparison with the mechanically ventilated buildings, the equivalent ratio was found slightly higher.

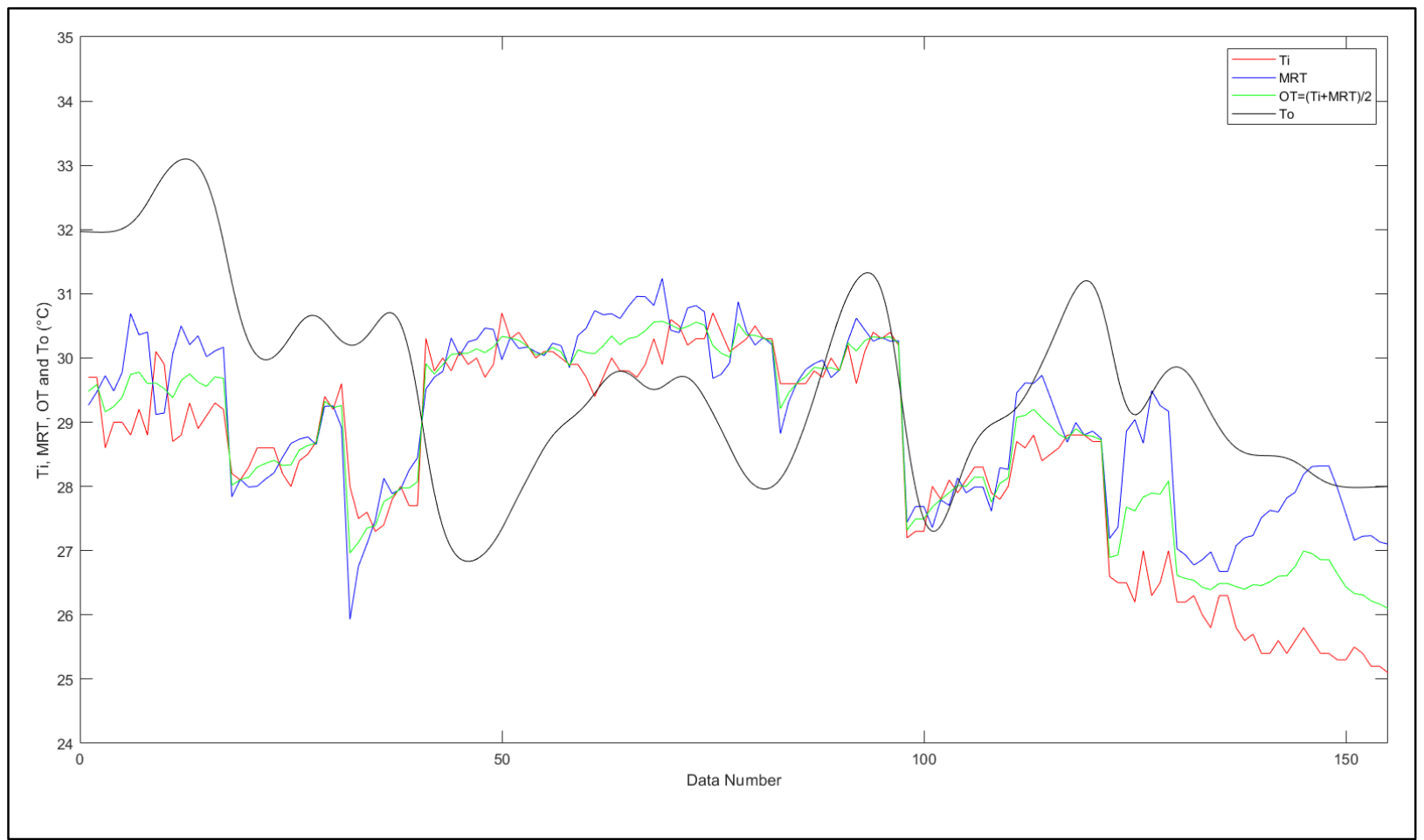

Figure 5. An example of measured values of $T_{i}$, MRT, OT and $T_{o}$. 
Table 3 indicates the standard deviations (SD), mean values of MRT and $\mathrm{T}_{\mathrm{i}}$ and $\mathrm{t} \& \mathrm{p}$ values.

Table 3. Statistical values of the study.

\begin{tabular}{|c|c|c|}
\hline & MRT & $\mathbf{T}_{\mathbf{i}}$ \\
\hline SD & 1.27 & 1.64 \\
\hline Mean & 29.05 & 28.45 \\
\hline t-value & \multicolumn{2}{|c|}{4.18} \\
\hline p-value & \multicolumn{2}{|c|}{.001} \\
\hline
\end{tabular}

The two-tailed $t$-test revealed that the null hypothesis was rejected since the p-value was found lower than the significance value, which was selected .05 in the study.
Therefore, the equality of MRT and $T_{i}$ hypothesis was rejected, and the alternative hypothesis was accepted.

Figure 6 depicts the effect of using the assumption of the equality of MRT and $\mathrm{T}_{\mathrm{i}}$ to the ATC standards for acceptable limits of $80 \%$ and $90 \%$, respectively. A significant difference was observed in both $80 \%$ and $90 \%$ acceptable limits. While comparing the OT data for $80 \%$ acceptance limit, using assumption changes the OT data of $30.4 \%$ to the out of the upper and lower acceptable limits. In the other side, the assumption changes the OT data of $27.4 \%$ out of the upper and lower acceptable limits of $90 \%$.

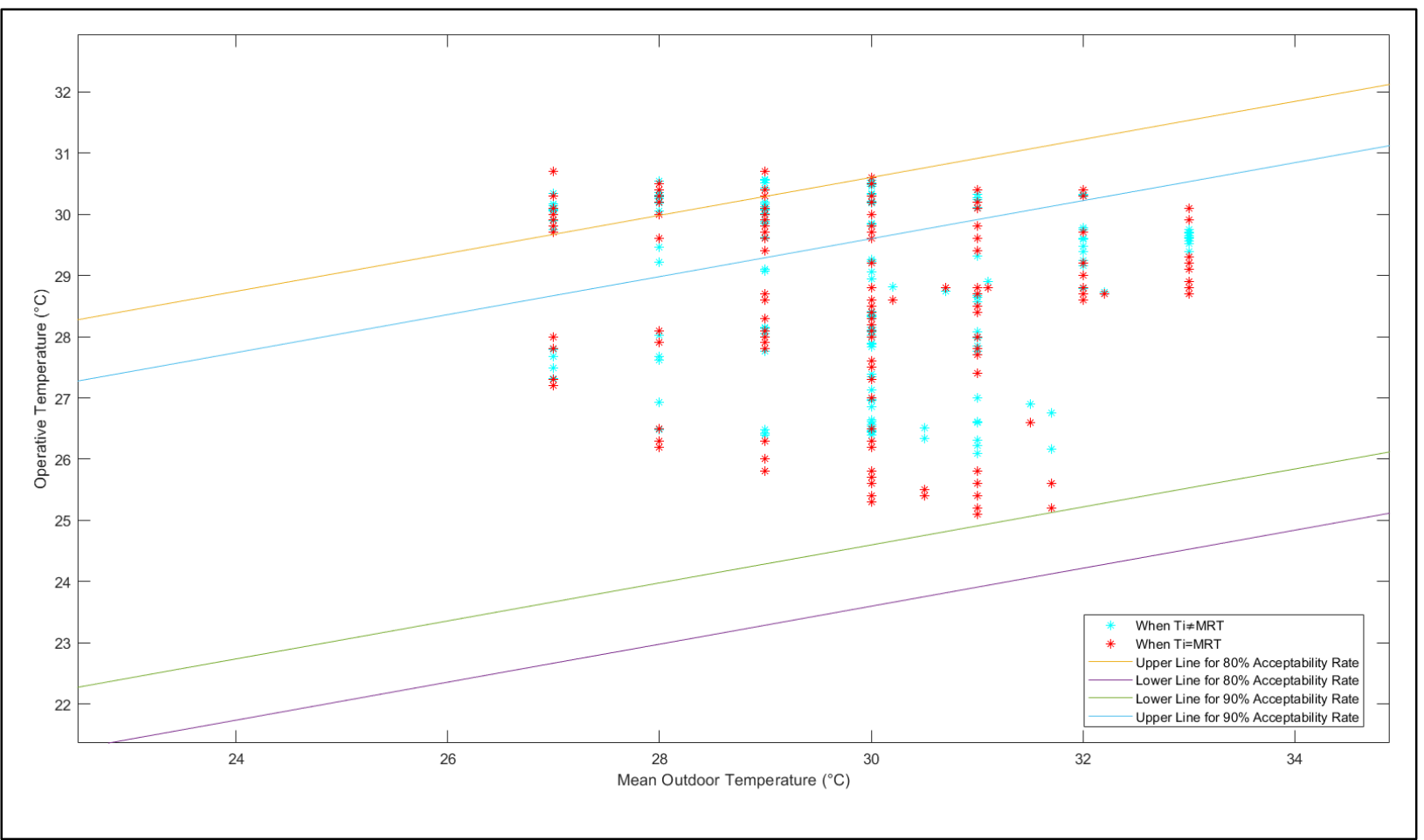

Figure 6. Adaptive thermal comfort charts for $80 \%$ and $90 \%$ acceptance limits with temperature data.

\section{Conclusions}

The MRT is the most crucial and difficult to obtain one of the environmental parameters which affect thermal comfort. There are three different methods to obtain to MRT in the indoor environment, which are calculation, measurement method and assumptions. The calculation methods are not preferred since its complexity and challenging calculation steps, and measurement methods are not chosen to obtain MRT due to the cost of equipment. Therefore, the MRT values are generally obtained by using the assumption of the equality of MRT and $T_{i}$ in various studies because of its easiness. However, using this assumption brings along the uncertainty about the accuracy of the assumption.

The evidence from this study discussed the accuracy of the assumption. The findings of this study do not support the idea of using the assumption of the equality of MRT and $T_{i}$ in summer conditions for freerunning buildings by using the linear comparative method and two-sample $t$-test method.

As a result of applied methods, $\mathrm{R}^{2}$ was found 0.66 and $\mathrm{p}$-value was found .001 . Besides, the equivalent ratio was depicted 0.853 , which slightly higher than previous findings of mechanically ventilated buildings [16-18].

This study clearly has some limitations. As a first limitation, the occupant, who was inside the case building while taking the measurements, was an 
additional heat source to the environment. Therefore, the MRT and $\mathrm{T}_{\mathrm{i}}$ values could be affected from the occupant. Secondly, this study only examined the accuracy of the assumption in the summer season. The result should be discussed for winter condition in a free-running building. In winter conditions, since the radiative heat diffuses from the human body to the outside, the MRT is expected to be lower than the indoor air temperature. Furthermore, solar radiation values will be different as discussed in $[1,34]$.

As future work, further experimental studies will determine the accuracy of the assumption also for the lower values of the MRT and $\mathrm{T}_{\mathrm{i}}$.

\section{Declaration of Ethical Standards}

The authors of this article declare that the materials and methods used in this study do not require ethical committee permission and/or legal-special permission.

\section{Conflict of Interest}

The authors declare that they have no known competing financial interests or personal relationships that could have appeared to influence the work reported in this paper.

\section{References}

[1] ASHRAE 55, 2017, Thermal Environmental Conditions for Human Occupancy

[2] ISO Standard 7730, 1994, Moderate Thermal Environments-Determination of the PMV and PPD Indices and Specification of the Conditions for Thermal Comfort, International Standards Organization, Geneva, Switzerland.

[3] Fanger, P.O., 1970. Thermal comfort. Analysis and applications in environmental engineering. Thermal comfort. Analysis and applications in environmental engineering.

[4] Nicol, F. and Humphreys, M., 2010. Derivation of the adaptive equations for thermal comfort in freerunning buildings in European standard EN15251. Building and Environment, 45(1), pp.11-17.

[5] De Dear, R.J. and Brager, G.S., 2002. Thermal comfort in naturally ventilated buildings: revisions to ASHRAE Standard 55. Energy and Buildings, 34(6), pp.549-561.

[6] Wagner, A., Gossauer, E., Moosmann, C., Gropp, T. and Leonhart, R., 2007. Thermal comfort and workplace occupant satisfaction-Results of field studies in German low energy office buildings. Energy and Buildings, 39(7), pp.758-769.

[7] Pfafferott, J., Herkel, S., Kalz, D.E. and Zeuschner, A., 2007. Comparison of low-energy office buildings in summer using different thermal comfort criteria. Energy and Buildings, 39(7), pp.750-757.

[8] CEN EN 15251, 2007. Indoor Environmental Input Parameters for Design and Assessment of Energy Performance of Buildings Addressing Indoor Air Quality. Thermal Environment. Lighting and Acoustics. European Committee for Standardization. Brussels, Belgium.

[9] Van der Linden, A.C., Boerstra, A.C., Raue, A.K., Kurvers, S.R. and De Dear, R.J., 2006. Adaptive temperature limits: A new guideline in The Netherlands: A new approach for the assessment of building performance with respect to thermal indoor climate. Energy and Buildings, 38(1), pp.817.

[10] Kántor, N. and Unger, J., 2011. The most problematic variable in the course of humanbiometeorological comfort assessment-the mean radiant temperature. Central European Journal of Geosciences, 3(1), pp.90-100.

[11] Wang, Y., Meng, X., Zhang, L., Liu, Y. and Long, E., 2014. Angle factor calculation for the thermal radiation environment of the human body. In Proceedings of the 8th International Symposium on Heating, Ventilation and Air Conditioning (pp. 447455). Springer, Berlin, Heidelberg.

[12] JOKL, M.V., 2015. 4 New Thermal Comfort Standards of the Czech Republic. Standards for Thermal Comfort: Indoor air temperature standards for the 21 st century.

[13] ROWE, D., 2015. 24 Warm and Sweaty: Thermal Comfort in Two Naturally Ventilated Offices in Sydney, NSW. Standards for Thermal Comfort: Indoor air temperature standards for the $21 \mathrm{st}$ century, p.48.

[14] Itani, M., Ghaddar, N., Ghali, K. and Laouadi, A., 2020. Development of heat stress charts for older people under indoor environmental conditions. Energy and Buildings, 224, p.110274.

[15] Dawe, M., Raftery, P., Woolley, J., Schiavon, S. and Bauman, F., 2020. Comparison of mean radiant and air temperatures in mechanically-conditioned commercial buildings from over 200,000 field and laboratory measurements. Energy and Buildings, 206, p. 109582. 
[16] Guo, H., Aviv, D., Loyola, M., Teitelbaum, E., Houchois, N., and Meggers, F., 2020. On the understanding of the mean radiant temperature within both the indoor and outdoor environment, a critical review. Renewable and Sustainable Energy Reviews, 117, 109207.

[17] Koch, W., 1962. Relationship between air temperature and mean radiant temperature in thermal comfort. Nature, 196(4854), pp.587-587.

[18] McIntyre, D.A. and Griffiths, I.D., 1972. Subjective response to radiant and convective environments. Environmental Research, 5(4), pp.471-482.

[19] Lin, B., Wang, Z., Sun, H., Zhu, Y. and Ouyang, Q., 2016. Evaluation and comparison of thermal comfort of convective and radiant heating terminals in office buildings. Building and Environment, 106, pp.91-102.

[20] Catalina, T., Virgone, J. and Kuznik, F., 2009. Evaluation of thermal comfort using combined CFD and experimentation study in a test room equipped with a cooling ceiling. Building and Environment, 44(8), pp.1740-1750.

[21] Chaudhuri, T., Soh, Y.C., Bose, S., Xie, L. and Li, H., 2016, October. On assuming Mean Radiant Temperature equal to air temperature during PMVbased thermal comfort study in air-conditioned buildings. IECON 2016-42nd Annual Conference of the IEEE Industrial Electronics Society (pp. 7065-7070). IEEE.

[22] Köppen-Geiger Climate Classification, 2009. Retrieved March 3, from http://koeppengeiger.vuwien.ac.at/ (Access Date: 30/11/2020)

[23] EN 16798, 2019. Energy performance of buildings Part 1: Indoor environmental input parameters for design and assessment of energy performance of buildings addressing indoor air quality, thermal environment, lighting and acoustics.

[24] Extech Instruments 42530, http://www.extech.com/display/?id=14256, (Access Date: 30/11/2020)

[25] TESTO 425 - Compact Thermal Anemometer, https://www.testo.com/en-UK/testo-425/p/05604251, (Access Date: 30/11/2020)

[26] ISO 7726, 1998. Ergonomics of the Thermal Environment-Instruments for Measuring Physical Quantities.

[27] Camacho, A., Rodrigues, M.T. and Navas, C., 2015.
Extreme operative temperatures are better descriptors of the thermal environment than mean temperatures. Journal of thermal biology, 49, pp.106-111.

[28] Kazkaz, M. and Pavelek, M., 2013. Operative temperature and globe temperature. Eng. Mech, 20(3/4), pp.319-325.

[29] Allen, M.P., 2004. Understanding regression analysis. Springer Science \& Business Media.

[30] Dekking, F.M., Kraaikamp, C., Lopuhaä, H.P. and Meester, L.E., 2005. A Modern Introduction to Probability and Statistics: Understanding why and how. Springer Science \& Business Media.

[31] Schechtman, E. and Sherman, M., 2007. The twosample t-test with a known ratio of variances. Statistical Methodology, 4(4), pp.508-514.

[32] Rumsey, D. J., 2016. Statistics For Dummies, 2nd ed., John Wiley \& Sons, Nashville, TN.

[33] Bughrara, K.S., Arsan, Z.D. and Akkurt, G.G., 2017. Applying underfloor heating system for improvement of thermal comfort in historic mosques: the case study of Salepçioğlu Mosque, Izmir, Turkey. Energy Procedia, 133, pp.290-299.

[34] Walikewitz, N., Jänicke, B., Langner, M., Meier, F., and Endlicher, W., 2015. The difference between the mean radiant temperature and the air temperature within indoor environments: A case study during summer conditions. Building and Environment, 84, 151-161. 